\title{
Loss of smell in patients with COVID-19
}

MRI data reveal a transient edema of the olfactory clefts

\author{
Michael Eliezer, MD, Anne-Laurel Hamel, MD, Emmanuel Houdart, MD, PhD, Philippe Herman, MD, PhD, \\ Juliette Housset, MD, Clement Jourdaine, MD, Corinne Eloit, MD, Benjamin Verillaud, MD, and \\ Charlotte Hautefort, MD
}

Neurology ${ }^{\circledR}$ 2020;95:e3145-e3152. doi:10.1212/WNL.0000000000010806

\section{Abstract}

\section{Objective}

To assess the physiopathology of olfactory function loss (OFL) in patients with coronavirus disease 2019 (COVID-19), we evaluated the olfactory clefts (OC) on MRI during the early stage of the disease and 1 month later.

\section{Methods}

This was a prospective, monocentric, case-controlled study. Twenty severe acute respiratory syndrome coronavirus 2 (SARS-CoV2)-infected patients with OFL were included and compared to 20 age-matched healthy controls. All infected patients underwent olfactory function assessment and $3 \mathrm{~T} \mathrm{MRI}$, performed both at the early stage of the disease and at the 1-month follow-up.

\section{Results}

At the early stage, SARS-CoV2-infected patients had a mean olfactory score of $2.8 \pm 2.7$ (range 0-8), and MRI displayed a complete obstruction of the OC in 19 of 20 patients. Controls had normal olfactory scores and no obstruction of the OC on MRI. At the 1 month follow-up, the olfactory score had improved to $8.3 \pm 1.9$ (range 4-10) in patients, and only 7 of 20 patients still had an obstruction of the OC. There was a correlation between olfactory score and obstruction of the OC $(p=0.004)$.

\section{Conclusion}

OFL in SARS-CoV2-infected patients is associated with a reversible obstruction of the OC.

\author{
Correspondence \\ Dr. Eliezer \\ michael.eliezer@aphp.fr
}

\section{MORE ONLINE}

\section{COVID-19 Resources}

For the latest articles, invited commentaries, and blogs from physicians around the world NPub.org/COVID19 


\section{Glossary}

ACE2 = angiotensin-converting enzyme 2; COVID-19 = coronavirus disease 2019; FLAIR = fluid-attenuated inversion recovery; $\mathrm{OB}=$ olfactory bulbs; $\mathrm{OC}$ = olfactory clefts; $\mathrm{OFL}=$ olfactory function loss; SARS-CoV2 = severe acute respiratory syndrome coronavirus 2 ; VOS = visual olfactive score.

Coronavirus disease 2019 (COVID-19), caused by severe acute respiratory syndrome coronavirus 2 (SARS-CoV2), infects mostly the human upper respiratory tracts, causing dry cough and dyspnea. ${ }^{1-4}$ Some patients also experienced nonspecific symptoms such as diarrhea and headache. ${ }^{5,6}$ A recent meta-analysis has reported a prevalence of self-reported olfactory function loss (OFL) among SARS-CoV2-infected patients as high as $52.7 \%{ }^{6}$ However, 2 studies have demonstrated that some patients with COVID-19 were aware of their olfactory deficit, while a quantitative olfactory deficit (with objective olfactory function tests) was observed in a greater proportion. ${ }^{7,8}$ In contrast, it has recently been reported that only $62 \%$ of patients with COVID- 19 with self-reported OLF had a deficit on objective psychophysical olfactory evaluation. ${ }^{9}$ Recent studies have shown a high rate of quick recovery of olfactory disorders. ${ }^{10,11}$ On the basis of this observation, Vaira et al. ${ }^{11}$ questioned the link between olfactory disorders and viral damage to the neurosensory cells.

In some studies, the virus directly infects sensorineural cells, similar to other coronaviruses. ${ }^{12,13}$ According to this model, one expects direct damage to the olfactory sensory tract, with structural changes in the olfactory bulbs (OB) and pathways. Recent research studies demonstrated that angiotensinconverting enzyme 2 (ACE2) receptors are expressed in the olfactory epithelium but not in the olfactory neurons. ${ }^{14,15}$ These receptors are targeted by SARS-CoV2, which might explain the obstruction of the olfactory clefts (OC), as previously reported. ${ }^{16-18}$ In effect, edema of olfactory mucosa could be the result of the interaction between SARS-CoV2 and the ACE2 protein, the first mechanism of the OFL, preventing odorant molecules from reaching the olfactory epithelium. ${ }^{16}$

The main aim of this study was to assess both olfactory function and morphologic changes of the OC on MRI in patients with COVID-19 with OFL during the early stage of the disease and at the 1-month follow-up.

\section{Methods}

\section{Standard protocol approvals, registrations, and patient consents}

This study has been approved by the ethics committee of our hospital (No. 00006477). All participants provided informed consent.

\section{Patients}

This was a single-center prospective case-controlled imaging study. All participants gave their informed consent to the study. Patients with confirmed SARS-CoV2 infection, as confirmed by real-time PCR, and presenting with OFL for $<15$ days were prospectively included between March 23 and April 27, 2020. All patients underwent real-time PCR to confirm SARS-CoV2 infection.

The following baseline data were collected: age; sex; OFL history; associated olfactory symptoms; taste disorders; other ear-nose-throat symptoms, especially nasal obstruction; clinical history; and chronology of SARS-CoV2 symptoms.

Exclusion criteria included a history of olfactory dysfunction, in particular after head trauma, congenital olfactory dysfunction, chronic rhinosinusitis, nasal surgery, neurologic disorders, or contraindication to MRI.

Age-adjusted ( \pm 5 years) 1:1 controls were recruited among the medical staff on a voluntary basis. Exclusion criteria for controls included any history of olfactory dysfunction, chronic rhinosinusitis, neurologic disorders, or contraindication to MRI.

\section{Olfactory functional assessment}

All patients and controls underwent 2 olfactory functional assessments: at baseline (e.g., within the first 15 days after the onset of OFL) and then 1 month later.

A visual olfactive score (VOS) from 0 to 10 was recorded, and evaluation was performed to assess the ability to detect and identify odorants. With the forced choice method, ${ }^{19} 5$ odorants were tested for both detection and identification-acetic acid (vinegar), eugenol (clove), vanillin (vanilla), curry, and cinnamaldehyde (cinnamon) - and trigeminal sensitivity (acetic acid, vinegar). An olfactory detection and identification assessment was performed and scored from 0 to $10(0=$ presumed anosmia and $10=$ normal perception).

\section{Imaging}

All patients and controls underwent 3T MRI (Skyra; Siemens, Erlangen, Germany) with a 64-channel head coil on the same day as the consultations and the olfactory tests. We performed $2 \mathrm{D}$ coronal and 3D T2-weighted images covering the anterior and middle segments of the skull base. The $2 \mathrm{D}$ fast-spin echo coronal T2-weighted images were performed with the following parameters: repetition time 2,230 milliseconds, echo time 90 milliseconds, slice thickness $2 \mathrm{~mm}$, without interslice gap, field of view $130 \times 130 \mathrm{~mm}$, matrix $320 \times 256$, and scan time 2 minutes 45 seconds. We also performed a 3D-T2 sampling perfection with application optimized using different flip angle evaluation (SPACE) sequence with the 
following parameters: field of view $160 \times 160 \mathrm{~mm}$, repetition time 2,000 milliseconds, echo time 423 , matrix $320 \times 288$, flip angle $120^{\circ}$, number of excitations 2 , generalized autocalibrating partial parallel acquisition 2, and scan time 2 minutes 46 seconds. A second MRI was performed at the 1-month follow-up.

\section{Image analysis}

For each patient, MRIs were evaluated with Carestream Vue 12.1 (Capterra, Arlington, VA) by 2 radiologists (M.E. and E.H.) with 6 and 30 years of experience in head and neck imaging who were blinded to the clinical data.

The permeability of the OC was evaluated on 2D fast-spin echo coronal T2-weighted images. The OC is delimited superiorly by the cribriform plate, below the $\mathrm{OB}$, medially by the nasal septum, and laterally by the upper part of the middle and superior turbinates (figure 1). Obstruction of the OC was considered complete when the entire length (anterior and posterior) was involved.

We also evaluated the volume of the OB on 3D-T2 SPACE sequence and calculated it by contouring the $\mathrm{OB}$ manually. The software then calculated the volume (in cubic millimeters) of the OB (figure 1). The posterior landmarks of the OB were defined on MRI as when a round-shaped of the OB was still observed on the coronal slice, contrasting with the flattened shaped of the olfactory tract on the next slice.

\section{Statistical analysis}

Data were analyzed with $\mathrm{R}$ software version 3.5.3 (The $\mathrm{R}$ Foundation for Statistical Computing, Vienna, Austria). Between-group comparisons were analyzed with the Student $t$ test for continuous data to assess significant differences between the groups. The $\chi^{2}$ test was used for categorical data to evaluate significant differences in each group for the presence of OC obstruction.
Interrater agreement in OC obstruction was estimated with the Cohen $\kappa$ coefficient. For statistical analysis, in cases of discrepancies, the presence of $\mathrm{OC}$ obstruction evaluated by the most experienced radiologist was taken as an abnormal finding.

Continuous data are presented as the mean with SD. Sensitivity was estimated by taking the clinical examination as the gold standard. We report categorical data as frequency and percentages.

\section{Data availability}

Researchers can apply for access to anonymized data from the present study for well-defined research questions that are in line with the overall research agenda for the cohort. Please contact the corresponding author.

\section{Results}

\section{Population}

All patient characteristics are listed in the table.

There were 20 patients with SARS-CoV2 infection (10 men, 10 women) with a mean age of $34.6 \pm 8.8$ years (range 21-53 years). There were 20 healthy controls ( 12 men, 8 women) with a mean age of $33.9 \pm 7.8$ years (range $26-51$ years). No significant differences in the mean age $(p=0.85)$ and $\operatorname{sex}(p=0.41)$ of the healthy control and the patient groups were observed.

A sudden OFL was experienced by 18 of 20 (90\%) patients with SARS-CoV2 infection. The remaining 2 patients reported a progressive OFL. None of the patients had associated nasal obstruction. Dysgeusia was claimed by 17 of 20 patients (total 9 patients, partial 8 patients). Typical symptoms of SARS-CoV2 infection were present in all patients (fever 6 patients, cough 11 patients, myalgia 16 patients, dyspnea 2 patients).

Figure 1 Fifty-two-year-old female healthy control

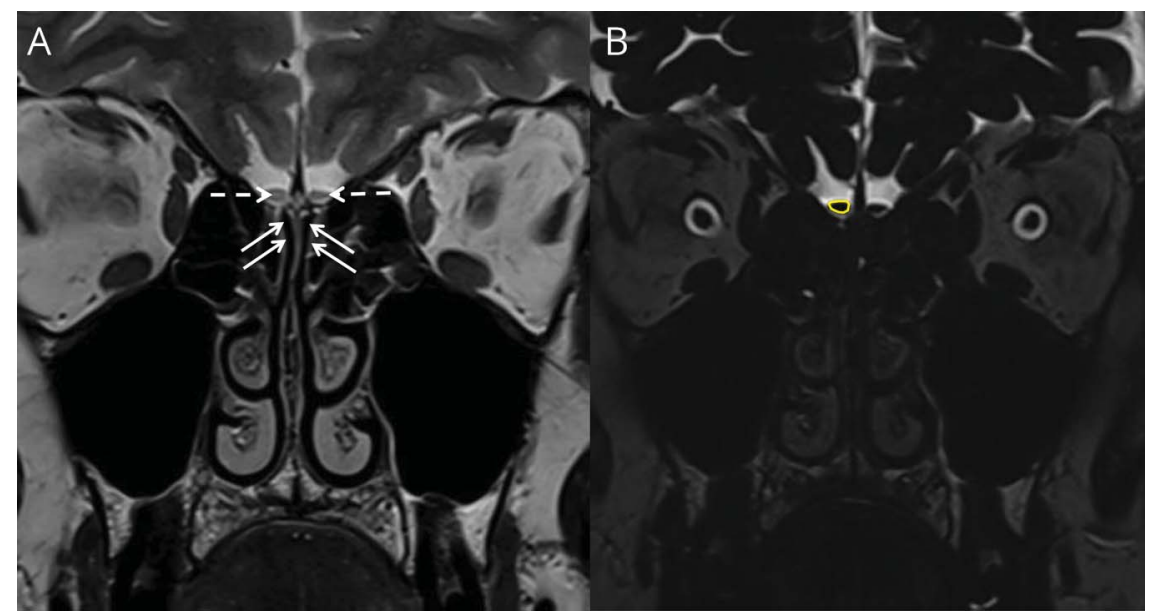

Coronal section of the olfactory clefts and bulbs on MRI on (A) 2D T2-weighted and (B) 3D T2weighted sequences. Olfactory bulbs (white dotted arrow) are normal (right $32.3 \mathrm{~mm}^{3}$, left $37.9 \mathrm{~mm}^{3}$ ), and the olfactory clefts (white arrow) are patent without inflammatory obstruction. 
Table Clinical and radiologic characteristics of patients with SARS-CoV2 infection and OFL

\begin{tabular}{|c|c|c|c|c|c|c|c|c|c|c|c|c|}
\hline \multicolumn{3}{|c|}{ Patients } & \multicolumn{5}{|c|}{ Early-stage MRI and olfactory functional assessment } & \multicolumn{5}{|c|}{ Follow-up MRI and olfactory functional assessment at $1 \mathrm{mo}$} \\
\hline \multirow[b]{3}{*}{ No. } & \multirow[b]{3}{*}{ Age, $y$} & \multirow[b]{3}{*}{ Sex } & \multicolumn{4}{|l|}{ MRI } & \multirow[b]{3}{*}{ Olfactory score } & \multicolumn{4}{|c|}{ MRI } & \multirow[b]{3}{*}{ Olfactory score } \\
\hline & & & \multicolumn{2}{|c|}{ OC obstruction } & \multicolumn{2}{|c|}{ OB volume, $\mathrm{mm}^{3}$} & & \multicolumn{2}{|c|}{ OC obstruction } & \multicolumn{2}{|c|}{ OB volume, $\mathrm{mm}^{3}$} & \\
\hline & & & $\mathbf{R}$ & $\mathbf{L}$ & $\mathbf{R}$ & $\mathbf{L}$ & & $\mathbf{R}$ & $\mathbf{L}$ & $\mathbf{R}$ & $\mathbf{L}$ & \\
\hline 1 & 27 & M & Yes & Yes & 33.9 & 51.3 & 0 & No & Yes & 49 & 43 & 8 \\
\hline 2 & 27 & $M$ & Yes & Yes & 43.1 & 41.4 & 2 & No & No & 30 & 26.6 & 8 \\
\hline 3 & 31 & $M$ & Yes & Yes & 32.7 & 34.8 & 0 & No & No & 25.5 & 17 & 10 \\
\hline 4 & 27 & $\mathrm{~F}$ & Yes & Yes & 36.8 & 32 & 0 & No & No & 20.6 & 19.5 & 10 \\
\hline 5 & 26 & $M$ & Yes & Yes & 60.2 & 61 & 7 & No & No & 57.7 & 54.5 & 10 \\
\hline 6 & 50 & $M$ & Yes & No & 36.7 & 40.4 & 0 & No & No & 44.8 & 38.3 & 10 \\
\hline 7 & 32 & $\mathrm{~F}$ & Yes & Yes & 33.2 & 43.4 & 1 & Yes & No & 39.8 & 30 & 8 \\
\hline 8 & 53 & $M$ & Yes & Yes & 33.2 & 39.1 & 0 & Yes & Yes & 38.2 & 41.9 & 5 \\
\hline 9 & 47 & $\mathrm{~F}$ & Yes & Yes & 56.2 & 43.2 & 1 & Yes & No & 49.2 & 51.2 & 9 \\
\hline 10 & 34 & $\mathrm{~F}$ & Yes & Yes & 31 & 32.5 & 5 & No & Yes & 33.8 & 27.3 & 9 \\
\hline 11 & 38 & $\mathrm{~F}$ & Yes & Yes & 32.8 & 42.1 & 3 & No & No & 29.2 & 39.3 & 10 \\
\hline 12 & 40 & $\mathrm{~F}$ & Yes & Yes & 38.1 & 36.3 & 1 & No & No & 36.9 & 41.9 & 7 \\
\hline 13 & 29 & $\mathrm{~F}$ & No & Yes & 48.3 & 40.9 & 7 & No & No & 39.8 & 41.9 & 9 \\
\hline 14 & 41 & $\mathrm{~F}$ & Yes & Yes & 24.1 & 32.1 & 8 & No & No & 28 & 33.8 & 10 \\
\hline 15 & 27 & $\mathrm{~F}$ & Yes & Yes & 32.2 & 31.6 & 5 & No & No & 33.3 & 32.4 & 9 \\
\hline 16 & 21 & $\mathrm{~F}$ & Yes & Yes & 46.8 & 45 & 7 & No & No & 49.5 & 51.4 & 10 \\
\hline 17 & 27 & $M$ & Yes & Yes & 42.3 & 46.2 & 4 & No & Yes & 42.8 & 55 & 4 \\
\hline 18 & 35 & $M$ & Yes & No & 44.2 & 48.4 & 3 & Yes & No & 43.8 & 56.6 & 10 \\
\hline 19 & 47 & $M$ & No & No & 27.5 & 22.3 & 0 & No & No & 28.8 & 23.7 & 5 \\
\hline 20 & 42 & $M$ & No & No & 30.8 & 40.7 & 1 & No & No & 41.5 & 38.6 & 6 \\
\hline
\end{tabular}

Abbreviations: $\mathrm{OB}=$ olfactory bulbs; OC = olfactory clefts; OFL = olfactory function loss; SARS-CoV2 = severe acute respiratory syndrome coronavirus 2.

\section{Olfactory functional assessment}

For healthy controls, the mean olfactory score was $9.4 \pm 0.7$ (range 8-10).

For patients with SARS-CoV2 infection, the mean delay between the onset of OFL and olfactory tests was $5.9 \pm 3.2$ days (range 1-13 days). At the time of the first consultation, the mean VOS was $1.6 \pm 1.9$ (range 0-6), while the mean olfactory score was $2.8 \pm 2.7$ (range $0-8$ ). There were 5 patients with a score of 0 and 15 patients with a score $<8$. There was a significant difference in the mean olfactory score between healthy controls and patients with SARS-CoV2 infection $(p<$ $0.001)$.

At the 1-month follow-up, the mean VOS and the mean olfactory score had improved to $7.4 \pm 2.6$ (range 1-10) and 8.3 \pm 1.9 (range 4-10), respectively (figure 2). Four patients had recovered a normal olfactory function with a visual olfactory score of 10 , and 4 patients had almost recovered with a score of 9. There was a significant difference in the mean olfactory score between the initial test and the second test performed at the 1-month follow-up in patients with SARS-CoV2 infection $(p<0.01)$.

\section{Imaging data}

The mean delay between the initial onset of OFL and MRI was $5.9 \pm 3.2$ days (range $1-13$ days).

\section{Obstruction of the OC}

In healthy controls, complete obstruction of the OC was never observed. The interrater agreement for OC obstruction was 1.

In patients with SARS-CoV2 infection, complete obstruction of the OC was observed in 19 of 20 patients ( 1 right-side, 1 left-side, 17 bilateral) on the first MRI. One patient had no OC obstruction. In this patient, the MRI was performed 11 days after the onset of OFL. There was a significant difference 
Figure 2 Mean olfactory score at first consultation and 1 -month follow-up in patients with severe acute respiratory syndrome coronavirus 2

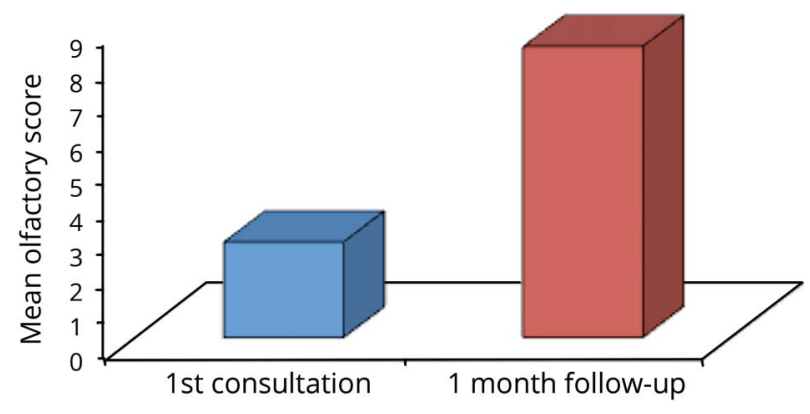

in OC obstruction between patients with SARS-CoV2 infection and controls $(p<0.001)$. The interrater agreement for OC obstruction was 0.9 .

At the 1-month follow-up, 12 of 19 patients with initial obstruction of the OC had recovered a normal patency of the OC. Altogether, a complete obstruction of the OC was still observed at the 1-month follow-up in only 7 of 20 patients ( 3 right-side, 3 left-side, 1 bilateral) (figures 3-5). Of these 7 patients with persistent obstruction of the OC, 5 of 6 patients with unilateral $\mathrm{OC}$ obstruction had an olfactory test score $\geq 8$, 1 patient with unilateral OC obstruction had an olfactory test score of 4 , and the only patient with bilateral OC obstruction had an olfactory score of 5 . The interrater agreement for OC obstruction was 0.77 .

There was a significant decrease in OC obstruction between the first and second MRIs $(p=0.004)$. We also found a significant correlation between the degree of OC obstruction and the severity of the olfactory score $(p=0.004)$. All patients except one, with bilateral patent OC on the second MRI, had recovered an olfactory score $\geq 8$. At the 1 -month follow-up, among the 4 SARS-CoV2-infected patients with OFL (score $<8), 2$ patients had OC obstruction (1 right-side, 1 bilateral) and 2 patients had no obstruction of the OC.

\section{OB volume}

In healthy controls, the mean $\mathrm{OB}$ volume was $37.5 \pm$ $13.2 \mathrm{~mm}^{3}$ on the right side and $36.4 \pm 13.7 \mathrm{~mm}^{3}$ on the left side.

In patients with SARS-CoV2 infection, the mean OB volume on the first MRI was $37.7 \pm 9.9 \mathrm{~mm}^{3}$ on the right side and 40.2 $\pm 8.8 \mathrm{~mm}^{3}$ on the left side. There was no significant difference in OB volume between patients with COVID-19 and healthy controls $(p=0.33)$.

At the 1-month follow-up, the mean $\mathrm{OB}$ volume was $38.1 \pm$ $9.5 \mathrm{~mm}^{3}$ on the right side and $38.2 .2 \pm 11.8 \mathrm{~mm}^{3}$ on the left side. There was no significant difference in $\mathrm{OB}$ volume between the first and second MRIs ( $p=0.97$ on the right side, $p=0.53$ on the left side).

\section{Discussion}

In this study, we report the olfactory functional test results and MRI findings in 20 patients with SARS-CoV2 infection associated with OFL at the first stage of the disease and at the 1-month follow-up.

The debate is still ongoing as to what extent the loss of smell in SARS-CoV2 infection is caused by congestion in the OC and/or direct damage to the olfactory sensory neurons, causing structural changes in the $\mathrm{OB}$ and pathways.

Here, at the early stage of the symptoms ( $<15$ days), we observed a complete obstruction of the OC in $95 \%$ of patients with SARS-CoV2 infection, which was likely to cause an impairment of the olfactory function by preventing odorant molecules from reaching the olfactory epithelium. Even if the origin of the OC obstruction remains uncertain, it has already been reported in patients with OFL after a severe nasopharyngeal infection. ${ }^{20}$ Only 1 of our patients had a slight diffuse mucosa hyperplasia, which was also observed in 1 healthy control. We believe that our patient corresponds to the definition of Biacabe et al., ${ }^{21}$ who described patients with isolated obstructed $\mathrm{OC}$ with clear sinuses or with a mild disease severity. Indeed, obstruction of the OC has also been reported in patients with chronic rhinosinusitis and sinonasal polyposis. ${ }^{21}$

At the 1-month follow-up, the OC obstruction was no longer present in 12 of 19 patients (63\%), and most of these patients had recovered from their olfactory loss, as evaluated with the VOS and 5-odorant molecules test. Indeed, SARS-CoV2 infects cells through interactions between its $S$ protein and the ACE2 protein on target cells. ${ }^{14,15}$ It has been reported that cells from the human nasal respiratory and support cells from the olfactory epithelium express ACE2 protein. ${ }^{22}$ Since that report, several others have hypothesized that this inflammatory obstruction of the OC might be the result of the interaction between SARS-CoV2 and ACE2 protein expressed by the olfactory epithelium. ${ }^{23}$

Figure 3 Mean OC obstruction on MRI at first consultation and 1 -month follow-up in patients with severe acute respiratory syndrome coronavirus 2

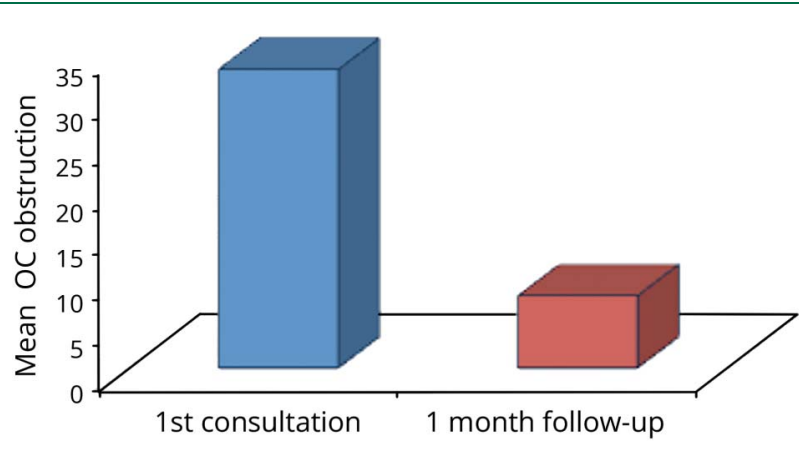

$\mathrm{OC}=$ olfactory clefts 

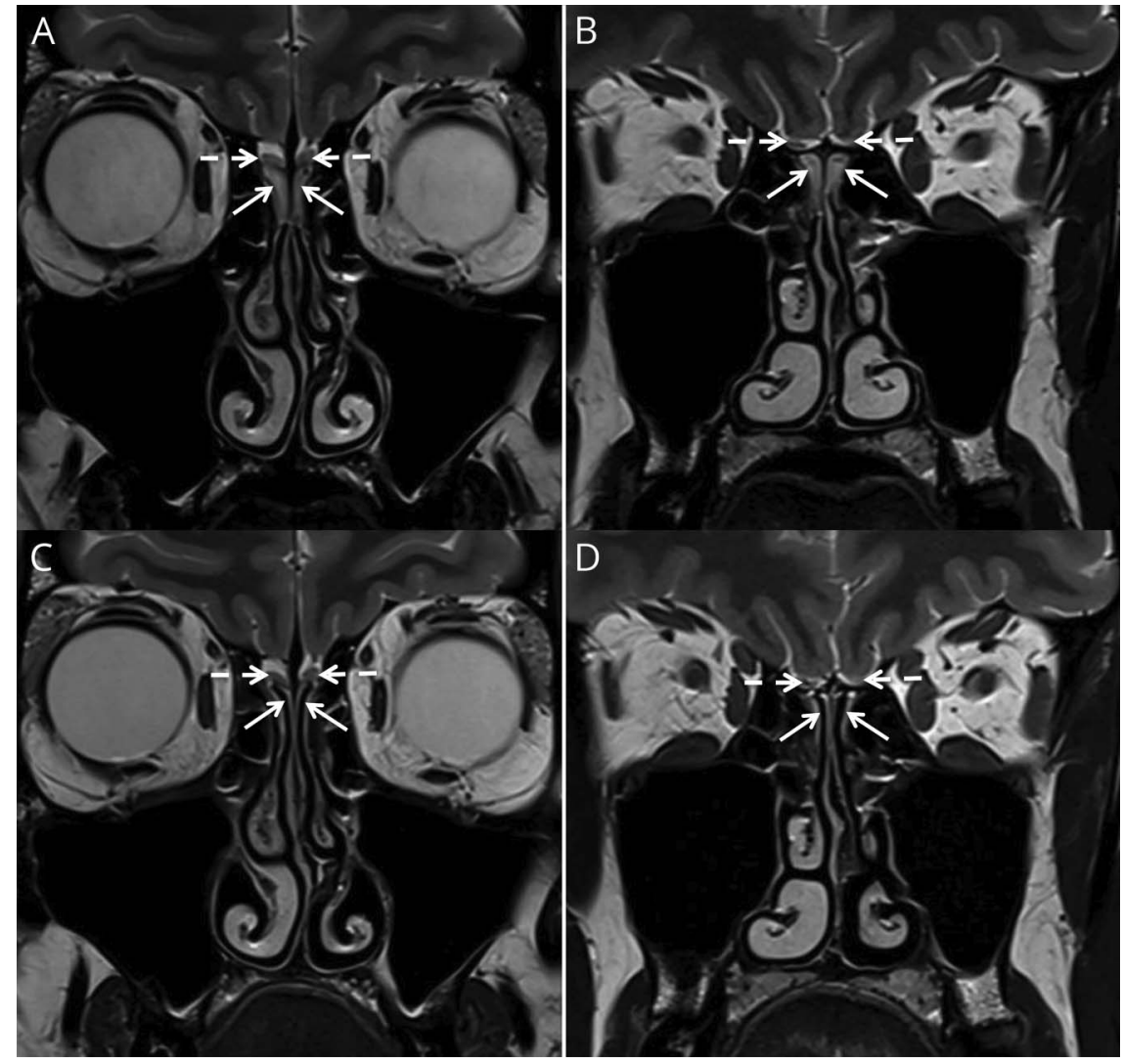

Coronal section of the olfactory clefts (OC) and bulbs on MRI on 2D T2-weighted sequences. (A and B) On the first MRI, the olfactory bulbs (white dotted arrow) are normal (right $38.1 \mathrm{~mm}^{3}$, left $42.1 \mathrm{~mm}^{3}$ ), while a bilateral inflammatory obstruction (white arrow) of the OC is observed below the olfactory bulbs ( $A$, white dotted arrow) and olfactory tracts (B, white dotted arrow). (C and D) At the 1-month follow-up, the volume of the olfactory bulbs (white dotted arrow) remains normal (right $29.2 \mathrm{~mm}^{3}$, left $39.3 \mathrm{~mm}^{3}$ ), and no inflammatory obstruction of the OC is observed within the (A) anterior and (B) posterior parts of the OC. The olfactory score at the first consultation and the 1-month follow-up was 0 and 10 respectively.

However, some scientific peers have questioned the inflammatory OC obstruction observed on MRI as the cause of the OFL because most patients did not appear to exhibit significant nasal congestion. ${ }^{24}$ In our opinion, the lack of this symptom seems conceivable because only $10 \%$ of inhaled air actually reaches the $\mathrm{OC}$ during normal resting breath. $^{25}$
It has also been suggested that SARS-CoV2 could invade the brain via the cribriform plate close to the $\mathrm{OB}$ and the olfactory epithelium, causing some structural changes in the OB. Recently, in a single case report, Laurendon et al. ${ }^{12}$ described MRI findings in a patient with SARS-CoV2 infection associated with a complete anosmia. MRI showed a bilateral obstruction of the OC, in addition to a severe enlargement and

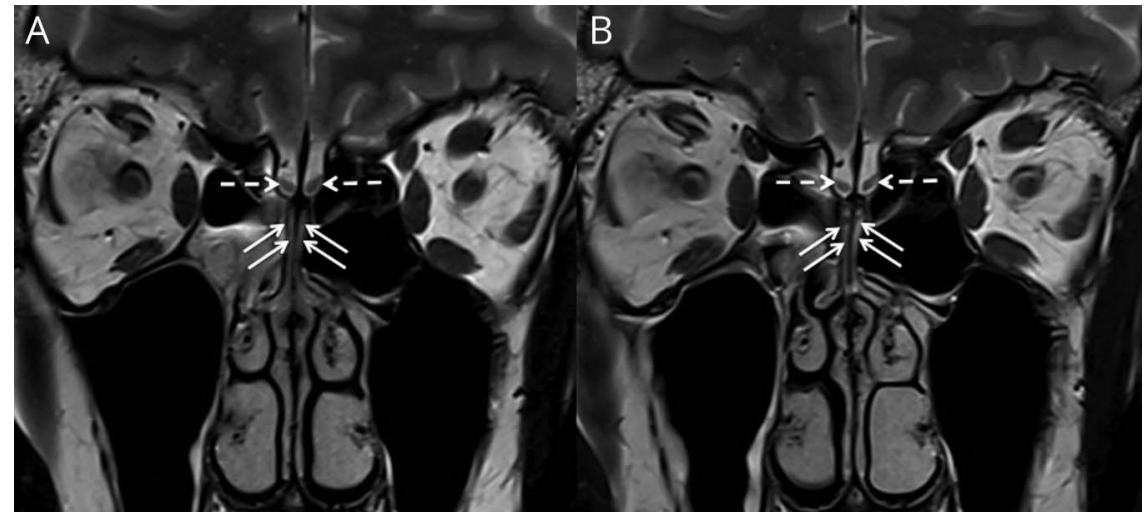

Coronal section of the olfactory clefts and bulbs on MRI on 2D T2-weighted sequences. (A and $B$ ) On the first MRI, the olfactory bulbs (white dotted arrow) are normal (right $33.2 \mathrm{~mm}^{3}$, left $39.1 \mathrm{~mm}^{3}$ ), while a bilateral inflammatory obstruction (white arrow) of the olfactory clefts is observed. (C and D) At the 1-month follow-up, the volume of the olfactory bulbs (white dotted arrow) remains normal (right $38.2 \mathrm{~mm}^{3}$, left $41.9 \mathrm{~mm}^{3}$ ), but an inflammatory obstruction of the OC (white arrow) is still observed. The olfactory score at the first consultation and the 1month follow-up was 0 and 5 , respectively. 
an abnormal high-signal intensity of the OB. A second MRI was performed 20 days after the initial onset of anosmia and showed a complete resolution of the OC obstruction and enlargement of the OB. Although we found a significant decrease in OC obstruction after 1 month of follow-up, we did not find the same results concerning $\mathrm{OB}$ changes. However a decreased neural activity in the olfactory pathways, despite normal morphology of the OB, seems conceivable. Galougahi et al. ${ }^{26}$ have reported a reduced metabolic activity in the orbitofrontal cortex in a patient with SARS-CoV2 infection and anosmia. Three of our patients without persistent OC obstruction still had loss of smell at the 1-month follow-up. One could hypothesize that the impairment of the neural function in the central olfactory pathways could occur secondarily after the initial OC obstruction. Moreover, in a recent single case, Politi et al. ${ }^{27}$ described a patient with SARS-CoV2 infection and anosmia that present a transient cortical fluid-attenuated inversion recovery (FLAIR) hyperintensity in the gyrus rectus and in the $\mathrm{OB}$ that might have result from invasion of SARS-CoV2 to the brain through the olfactory pathway.

Our study has several potential therapeutic implications. Preventing definitive anosmia in patients with SARS-CoV2 infection is crucial, considering that patients with OFL are at risk of nutritional deficits, depression, and injury due to the incapability to smell dangerous odors. ${ }^{28}$

The diagnosis of isolated OC obstruction is usually made in patients with a long history of OFL, and it is not possible to treat the potential initial cause of the disease, namely virus-induced inflammation of the OC. In these patients, most treatments actually do not work. ${ }^{20}$ Jankowski et al. ${ }^{29}$ have reported the results of surgical OC dilation in patients with dysosmia secondary to constitutional stenosis of the OC. The context is quite different in SARS-CoV2-infected patients, and this surgical option probably should not be considered first.

Our study has some limitations. First, our sample size was relatively small, which might explain some nonsignificant results. Second, because of its duration (40 odorants) and accessibility, the olfactory evaluations could not have been performed as usual with the University of Pennsylvanian Smell identification Test as a result of the sanitary crisis. ${ }^{30}$ Therefore, a visual scale and a test based on the forced choice method were chosen to assess the olfactory function. ${ }^{19} \mathrm{Nev}$ ertheless, given that many patients with COVID-19 are probably well aware of the association with the loss of smell, this could certainly affect the self-reporting VOS scores. In addition, a complete anosmia could not be confirmed because our quantitative test evaluates only 5 odorant molecules. Another limitation was the lack of fibroscopic examination with a standardized and validated scoring of the OC because of the sanitary situation. ${ }^{31}$

In addition, because 3D-FLAIR sequences were not performed in all patients (fewer than half of these patients), we could not exclude an impairment of the $\mathrm{OB}$, on the basis solely of the measure of their volume. Indeed, Yao et $\mathrm{al}^{32}$ have reported that the volume of the OB is decreased in patients with postinfectious olfactory loss and is inversely related to the duration of olfactory loss. However, cerebral and OB anomalies on 3D-FLAIR sequences have been reported in only 2 case reports.

Further prospective studies with follow-up are warranted to evaluate the prognostic value of this obstruction and the impairment of the central olfactory pathways.

This study evaluated the OC as well as the olfactory function in a cohort of patients with SARS-CoV2 infection presenting with OFL. Our results indicate that OFL and OC obstruction are present at the early stage of the disease and that both improved at the 1-month follow-up. These findings support the hypothesis that OFL in SARS$\mathrm{CoV} 2$-infected patients is caused, at least in part, by reversible inflammatory changes in the OC.

\section{Study funding}

No targeted funding reported.

\section{Disclosure}

The authors report no disclosures relevant to the manuscript. Go to Neurology.org/N for full disclosures.

\section{Publication history}

Received by Neurology August 5, 2020. Accepted in final form August 21, 2020.

\section{Appendix Authors}

\begin{tabular}{lll}
\hline Name & Location & Contribution \\
\hline $\begin{array}{ll}\text { Michael } \\
\text { Eliezer, MD }\end{array}$ & $\begin{array}{l}\text { AP-HP Lariboisière } \\
\text { Hospital, Paris, France }\end{array}$ & $\begin{array}{l}\text { Design and conceptualized } \\
\text { study; analyzed the data; } \\
\text { acquisition of data; drafted } \\
\text { the manuscript for intellectual } \\
\text { content }\end{array}$ \\
\end{tabular}

\begin{tabular}{lll}
\hline Anne-Laurel & AP-HP Lariboisière & $\begin{array}{l}\text { Analyzed the data; Acquisition } \\
\text { of data; revised the } \\
\text { Hamel, MD }\end{array}$ \\
Hospital, Paris, France & $\begin{array}{l}\text { manuscript for intellectual } \\
\text { content }\end{array}$
\end{tabular}

\begin{tabular}{lll}
\hline $\begin{array}{l}\text { Emmanuel } \\
\text { Houdart, } \\
\text { MD, PhD }\end{array}$ & $\begin{array}{l}\text { AP-HP Lariboisière } \\
\text { Hospital, Paris VII } \\
\text { University, France }\end{array}$ & $\begin{array}{l}\text { Analyzed the data; Revised the } \\
\text { manuscript for intellectual } \\
\text { content }\end{array}$ \\
\hline $\begin{array}{l}\text { Philippe } \\
\text { Herman, } \\
\text { MD, PhD }\end{array}$ & $\begin{array}{l}\text { AP-HP, Lariboisière } \\
\text { Hospital, Paris VII } \\
\text { University, France }\end{array}$ & $\begin{array}{l}\text { Revised the manuscript for } \\
\text { intellectual content }\end{array}$ \\
\hline $\begin{array}{l}\text { Juliette } \\
\text { Housset, MD }\end{array}$ & $\begin{array}{l}\text { AP-HP, Lariboisière } \\
\text { Hospital, Paris, France }\end{array}$ & Acquisition of data \\
\hline $\begin{array}{l}\text { Clement } \\
\text { Jourdaine, } \\
\text { MD }\end{array}$ & $\begin{array}{l}\text { AP-HP, Lariboisière } \\
\text { Hospital, Paris, France }\end{array}$ & $\begin{array}{l}\text { Interpreted the data; } \\
\text { statistical analysis }\end{array}$ \\
\hline $\begin{array}{l}\text { Corinne } \\
\text { Eloit, MD }\end{array}$ & AP-HP, Lariboisière & $\begin{array}{l}\text { Revised the manuscript for } \\
\text { intellectual content }\end{array}$ \\
\hline
\end{tabular}

Continued 
Appendix (continued)

\begin{tabular}{lll}
\hline Name & Location & Contribution \\
\hline $\begin{array}{l}\text { Benjamin } \\
\text { Verillaud, } \\
\text { MD, PhD }\end{array}$ & $\begin{array}{l}\text { AP-HP, Lariboisière } \\
\text { Hospital, Paris VII } \\
\text { University, France }\end{array}$ & $\begin{array}{l}\text { Analyzed the data; revised the } \\
\text { manuscript for intellectual } \\
\text { content }\end{array}$ \\
\hline $\begin{array}{l}\text { Charlotte } \\
\text { Mautefort, } \\
\text { MD }\end{array}$ & AP-HP, Lariboisière & $\begin{array}{l}\text { Designed and conceptualized } \\
\text { study; acquisition of data; } \\
\text { analyzed the data; revised the } \\
\text { manuscript for intellectual } \\
\text { content }\end{array}$ \\
\hline
\end{tabular}

\section{References}

1. World Health Organization. Coronavirus disease (COVID-19) outbreak. 2020. Available at: who.int/emergencies/diseases/novel-coronavirus-2019. Accessed February $15,2020$.

2. $\mathrm{Xu} \mathrm{X}$, Chen $\mathrm{P}, \mathrm{Wang} \mathrm{J}$, et al. Evolution of the novel coronavirus from the ongoing Wuhan outbreak and modeling of its spike protein for risk of human transmission. Sci China Life Sci 20203;63:457-460.

3. Tsang KW, Ho PL, Ooi GC, et al. A cluster of cases of severe acute respiratory syndrome in Hong Kong. N Engl J Med 2003;348:1977-1985.

4. Assiri A, Al-Tawfq JA, Al-Rabeeah AA, et al. Epidemiological, demographic, and clinical characteristics of 47 cases of Middle East respiratory syndrome coronavirus disease from Saudi Arabia: a descriptive study. Lancet Infect Dis 2013;13:752-761.

5. Huang C, Wang Y, Li X, et al. Clinical features of patients infected with 2019 novel coronavirus in Wuhan, China. Lancet 2020;395:497-506.

6. Tong JY, Wong A, Zhu D, Fastenberg JH, Tham T. The prevalence of olfactory and gustatory dysfunction in COVID-19 patients: a systematic review and meta-analysis. Otolaryngol Head Neck Surg 2020;163:3-11.

7. Moein ST, Hashemian SMR, Mansourafshar B, Khorram-Tousi A, Tabarsis P, Doty RL. Smell dysfunction: a biomarker for COVID-19, Int Forum Allergy Rhinol 2020; 10:944-950.

8. Hornuss D, Lange B, Schröter N, Rieg S, Kern WV, Wagner D. Anosmia in COVID19 patients. Clin Microbiol Infect Epub 2020 May 22.

9. Lechien JR, Cabaraux P, Chiesa-Estomba CM. Objective olfactory evaluation of selfreported loss of smell in a case series of 86 COVID-19 patients. Head Neck 2020;42: 1583-1590.

10. Kaye R, Chang CWD, Kazahaya K, Breretin J, Denneny JC III. COVID-19 anosmia reporting tool: initial findings. Otolaryngol Head Neck Surg 2020;163:132-134.

11. Vaira LA, Salzano G, Cucurullo M, et al. Olfactory and gustatory function impairment in COVID-19 patients: Italian objective multicenter-study. Head Neck 2020;42: $1560-1569$.

12. Laurendon T, Radulesco T, Mugnier J, et al. Bilateral transient olfactory bulbs edema during COVID-19 related anosmia. Neurology 2020:95:224-225.

13. Vaira LA, Salzano G, Fois AG, Piombino P, De Riu G. Potential pathogenesis of ageusia and anosmia in COVID-19 patients. Int Forum Allergy Rhinol 2020:10: 1103-1104.
14. Li YC, Bai WZ, Hashikawa T. The neuroinvasive potential of SARS-CoV2 may play a role in the respiratory failure of COVID-19 patients. J Med Virol 2020:92 552-555.

15. Bilinska K, Jakubowska P, Von Bartheld CS, Butow R. Expression of the SARS-CoV-2 entry proteins, ACE2 and TMPRSS2, in cells of the olfactory epithelium: identification of cell types and trends with age. ACS Chem Neurosci 2020:11:1555-1562.

16. Eliezer M, Hautefort C, Hamel AL, et al. Sudden and complete olfactory function loss as the main symptom of COVID-19. JAMA Otolaryngol Head Neck Surg 2020:82: $175-180$.

17. Eliezer M, Hautefort C. MRI evaluation of the olfactory clefts in patients with SARS CoV-2 infection revealed an unexpected mechanism for olfactory function loss. Acad Radiol 2020:27:1191.

18. Galougahi MK, Ghorbani J, Bakhshayeshkaram M, Naeini S, Haseli S. Olfactory bulb magnetic resonance imaging in SARS-CoV-2-induced anosmia: the first report. Acad Radiol 2020:27:892-893.

19. Landis BN, Hummel T, Lacroix J-S. Basic and clinical aspects of olfaction. Adv Tech Stand Neurosurg 2005;30:69-105.

20. Trotier D, Bensimon JL, Herman P, Tran Ba Huy P, Doving KB, Eloit C. Inflammatory obstruction of the olfactory clefs and olfactory loss in humans: a new syndrome? Chem Senses 2007;32:285-292.

21. Biacabe B, Faulcon P, Amanou L, Bonfils P. Olfactory cleft disease: an analysis of 13 cases. Otolaryngol Head Neck Surg 2004;130:202-208.

22. Sungnak W, Huang N, Bécavin C, Berg M; HCA Lung Biological Network. SARS CoV-2 entry genes are most highly expressed in nasal goblet and ciliated cells within human airways.ArXiv Epub 2010 Mar 13.

23. Brann DH, Tsukahara T, Weinreb C, et al. Non-neuronal expression of SARS-CoV-2 entry genes in the olfactory system suggests mechanisms underlying COVID-19associated anosmia. Sci Adv 2020;6:eabc5801.

24. Kheok SW, Yang N, Seligman B. Olfactory cleft involvement in COVID-19 patients with anosmia. JAMA Otolaryngol Head Neck Surg (in press 2020).

25. Zhao K, Scherer PW, Hajiloo SA, Dalton P. Effect of anatomy on human nasal air flow and odorant transport patterns: implications for olfaction. Chem Senses 2004;29: 365-379.

26. Galougahi MK, Yousefi-Koma A, Bakhshayesshkaram M, Raad N, Haseli S. ${ }^{18}$ FDG $\mathrm{PET} / \mathrm{CT}$ scan reveals hypoactive orbitofrontal cortex in anosmia of COVID-19. Acad Radiol 2020;27:1042-1043.

27. Politi LS, Salsano E, Grimaldi M. Magnetic resonance imaging alteration of the brain in a patient with coronavirus disease 2019 (COVID-19) and anosmia. JAMA Neurol Epub 2020 May 29.

28. Croy I, Nordin S, Hummel T. Olfactory disorders and quality of life-an updated review. Chem Senses 2014;39:185-194.

29. Jankowski R, Nguyen DT, Gallet P, Rumeau C. Olfactory cleft dilatation. Eur Ann Otorhinolaryngol Head Neck 2018; 135:437-441. Seiden, AM, Duncan HJ. The diagnosis of a conductive olfactory loss. Laryngoscope, 2001; 111(1), 9-14.

30. Doty RL, Shaman P, Dann M. Development of the University of Pennsylvania Smell Identification Test: a standardized microencapsulated test of olfactory function. Physiol Behav 1984;32:489-502.

31. Vandenhende-Szymanski C, Hochet B, Chevalier D, Mortuaire G. Olfactory cleft opacity and CT score are predictive factors of smell recovery after surgery in nasa polyposis. Rhinology 2015;53:29-34.

32. Yao L, Yi X, Pinto JM, et al. Olfactory cortex and Olfactory bulb volume alterations in patients with post-infectious olfactory loss. Brain Imaging Behav 2018;12: $1355-1362$ 


\section{Neurology}

\section{Loss of smell in patients with COVID-19: MRI data reveal a transient edema of the olfactory clefts}

Michael Eliezer, Anne-Laurel Hamel, Emmanuel Houdart, et al.

Neurology 2020;95;e3145-e3152 Published Online before print September 11, 2020

DOI 10.1212/WNL.0000000000010806

This information is current as of September 11, 2020

\section{Updated Information \&} Services

References

Citations

Subspecialty Collections

Permissions \& Licensing

Reprints including high resolution figures, can be found at: http://n.neurology.org/content/95/23/e3145.full

This article cites 27 articles, 2 of which you can access for free at: http://n.neurology.org/content/95/23/e3145.full\#ref-list-1

This article has been cited by 2 HighWire-hosted articles: http://n.neurology.org/content/95/23/e3145.full\#\#otherarticles

This article, along with others on similar topics, appears in the following collection(s):

MRI

http://n.neurology.org/cgi/collection/mri

Information about reproducing this article in parts (figures,tables) or in its entirety can be found online at:

http://www.neurology.org/about/about_the_journal\#permissions

Information about ordering reprints can be found online:

http://n.neurology.org/subscribers/advertise

Neurology ${ }^{\circledR}$ is the official journal of the American Academy of Neurology. Published continuously since 1951, it is now a weekly with 48 issues per year. Copyright @ 2020 American Academy of Neurology. All rights reserved. Print ISSN: 0028-3878. Online ISSN: 1526-632X.

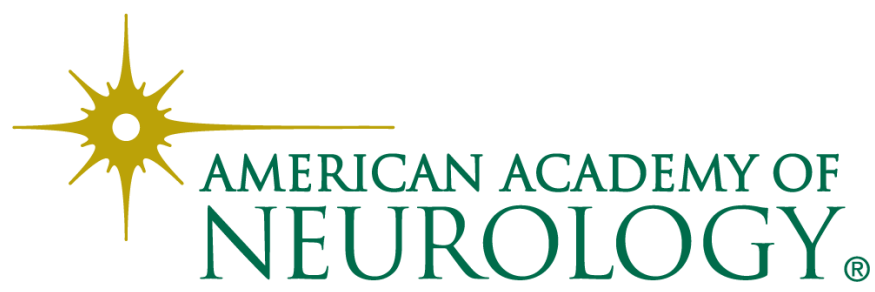

